\section{Endoscopic ultrasonography-guided transhepatic antegrade self-expandable metal stent placement in a patient with surgically altered anatomy}

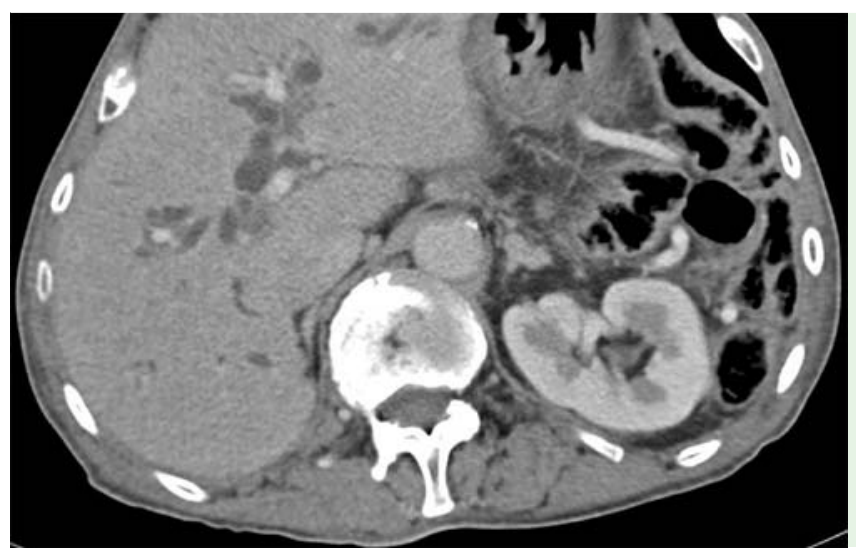

Fig. 1 Abdominal computed tomography shows dilatation of the intrahepatic biliary tree and stenosis of the hepaticojejunostomy in an 83-year-old man presenting with cholangitis. The patient had a history of distal pancreatectomy with splenectomy and a subsequent Whipple procedure.

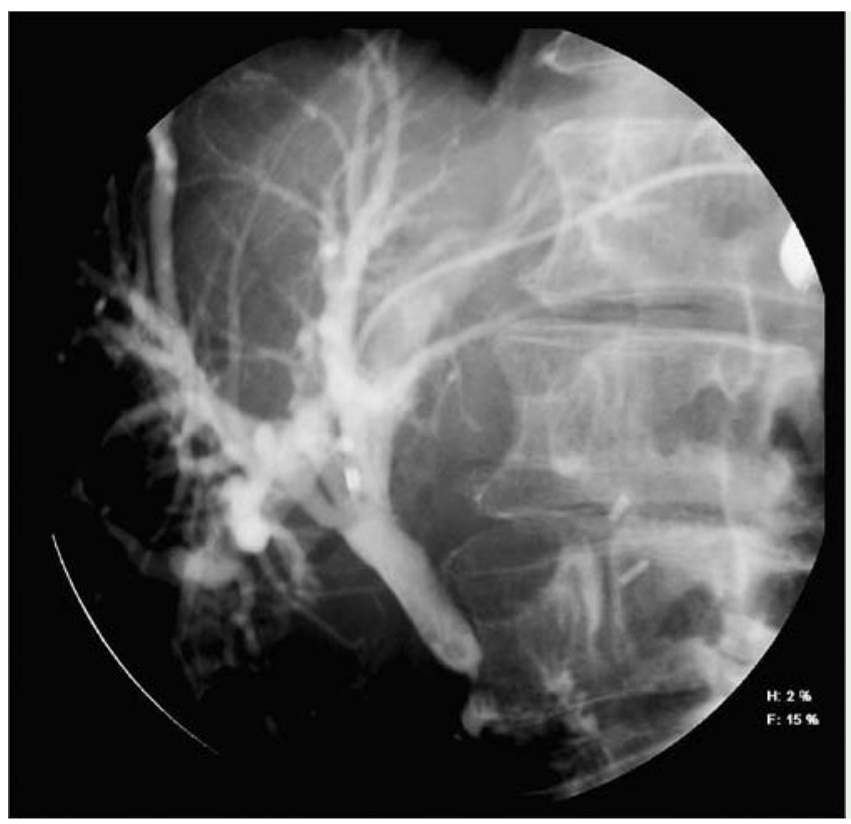

Fig. 2 Cholangiography shows dilatation of the intrahepatic and common hepatic ducts and stenosis of the hepaticojejunostomy.

An 83-year-old man who had a history of distal pancreatectomy with splenectomy and a subsequent Whipple procedure (both surgical procedures for metastatic renal cancer) presented to the emergency room with cholangitis (fever and jaundice), leukocytosis $\left(33900 / \mathrm{mm}^{3}\right)$, a total bilirubin level of $4.55 \mathrm{mg} / \mathrm{dL}$ (direct $3.7 \mathrm{mg} / \mathrm{dL}$ ), and elevated alkaline phosphatase $(780 \mathrm{U} / \mathrm{L})$. Abdominal computed tomography showed dilatation of the intrahepatic biliary tree and stenosis of the hepaticojejunostomy ( $\bullet$ Fig. 1).

Transgastric puncture of the left intrahepatic duct with a 19-gauge access nee-
Next, EUS-guided antegrade stent placement via the transhepatic route was accomplished. A $10-\mathrm{mm} \times 6-\mathrm{cm}$ uncovered self-expanding metallic stent (SEMS; Taewoong Medical, Seoul, South Korea) was advanced through a therapeutic echoendoscope over the guidewire and deployed across the stricture ( $\bullet$ Fig.5). Proper placement was confirmed by fluoroscopy, and there were no immediate complications. The patient was discharged home 7 days later in stable clinical condition and with resolved cholangitis.

Access to the biliary ducts in patients with surgically altered anatomy is challenging. Considerable experience with double-balloon enteroscopy (DBE) has been obtained, with good results; however, the procedure is technically difficult, timeconsuming, and not always available [1]. Access to the biliary tract with EUS guidance is a valuable resource in experienced hands [2], but there is little information about endoscopic antegrade transhepatic SEMS placement in patients with surgically altered anatomy [3]. We consider that EUS-guided transhepatic antegrade SEMS placement is a good alternative in patients with surgically altered anatomy when DBE has failed or is not available.

Endoscopy_UCTN_Code_TTT_1AS_2AD

Competing interests: None

Félix I. Téllez-Ávila, Gilberto DuarteMedrano, Víctor Gallardo-Cabrera, Luis Casasola-Sánchez, Francisco Valdovinos-Andraca

Department of Endoscopy, Instituto Nacional de Ciencias Médicas y Nutrición Salvador Zubirán, Mexico City, Mexico

\section{References}

1 Skinner M, Popa D, Neumann $H$ et al. ERCP with the overtube-assisted enteroscopy technique: a systematic review. Endoscopy 2014; 46: 560-572

2 Ramírez-Luna MA, Téllez-Ávila FI, Giovannini $M$ et al. Endoscopic ultrasound-guided biliodigestive drainage is a good alternative in patients with unresectable cancer. Endoscopy 2011; 43: 826-830

3 Nguyen-Tang T, Binmoeller KF, Sanchez-Yague $A$ et al. Endoscopic ultrasound (EUS)-guided transhepatic anterograde self-expandable metal stent (SEMS) placement across malignant biliary obstruction. Endoscopy 2010; 42: $232-236$ 


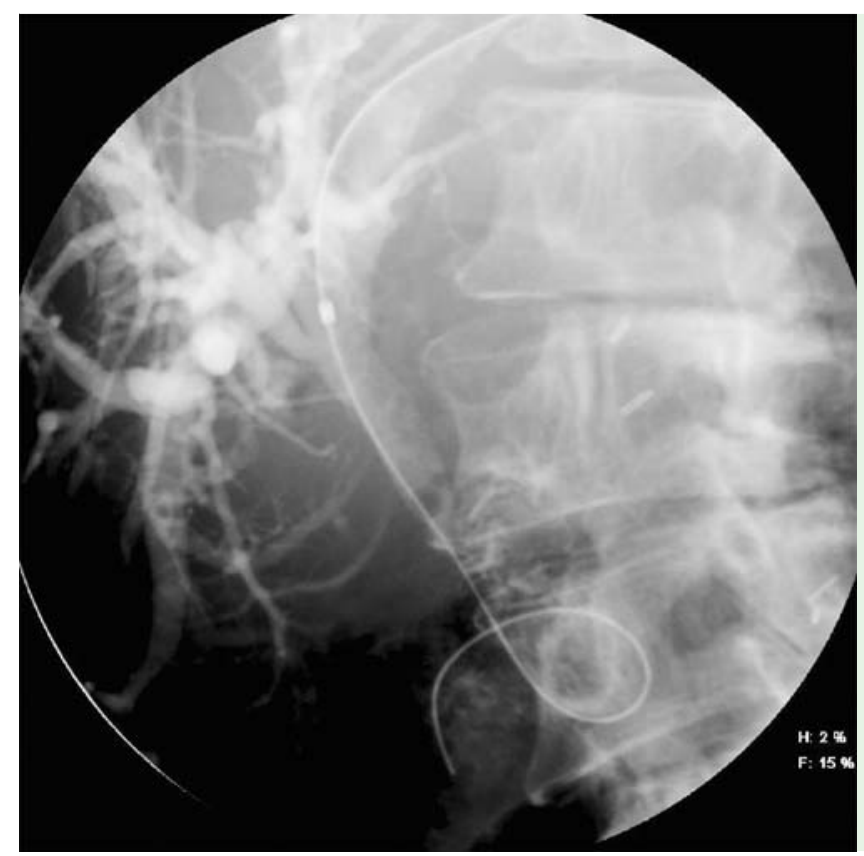

Fig. 3 A 0.035-inch guidewire reaches the jejunum, and Soehendra dilators are advanced over the wire.

\section{Bibliography}

Dol http://dx.doi.org/

10.1055/s-0034-1393671

Endoscopy 2015; 47: E643-E644

(c) Georg Thieme Verlag KG

Stuttgart · New York

ISSN 0013-726X

\section{Corresponding author}

\section{Félix I. Téllez-Âvila, MD, MSc, PhD}

Endoscopy Department

Instituto Nacional de Ciencias Médicas y Nutrición

Salvador Zubirán

Avenida Vasco de Quiroga No. 15

Colonia Belisario Dominguez Sección XVI

Delegación Tlalpan C.P. 14080

Ciudad de México

México

Fax: +52-55-5487-0900

felixtelleza@gmail.com
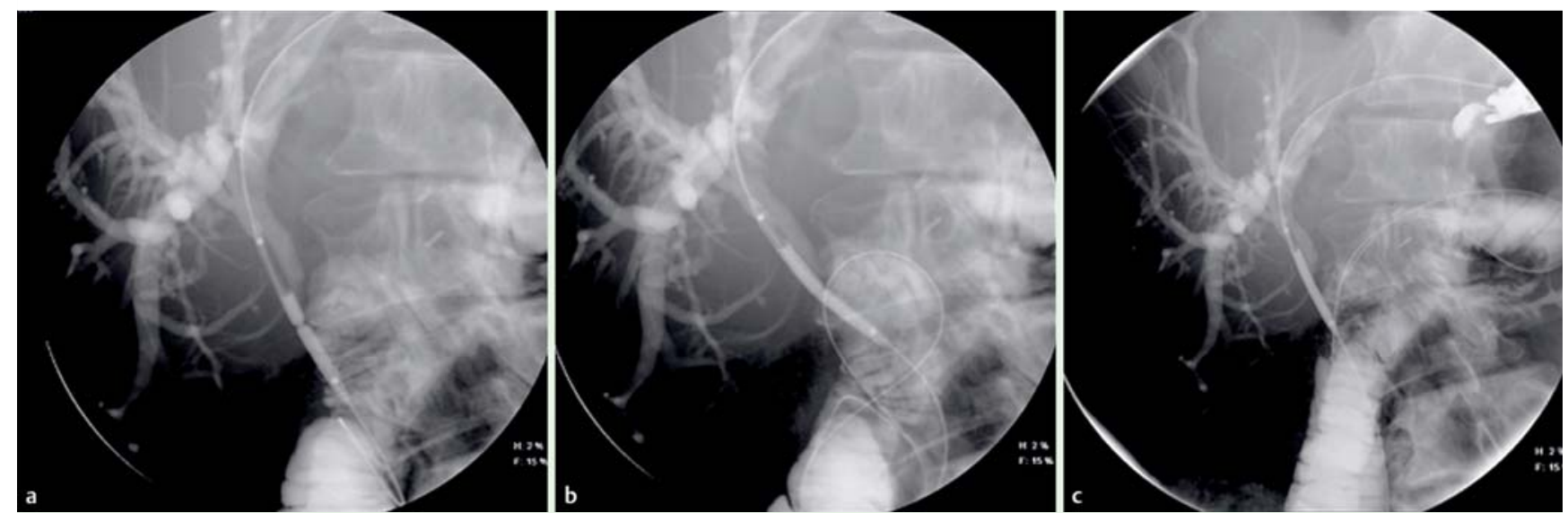

Fig. 4 A MaxForce balloon is used to dilate the stenosis. a The stricture is clearly seen in the middle. b Progressive dilation with the balloon. $\mathbf{c}$ The stricture is not visible at the end of the procedure.

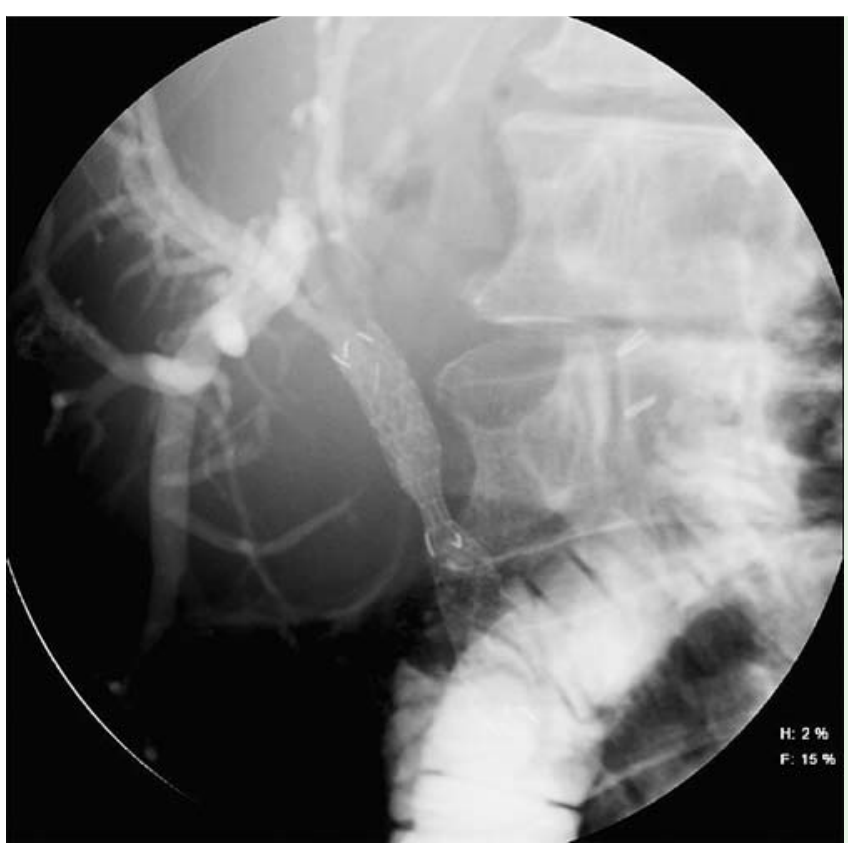

Fig. 5 The stent is

advanced through a

therapeutic echoendo-

scope over the guide-

wire and deployed

across the stricture. 